\title{
Development of Flood Tolerant Rice Variety: An Enhancement to Food Security in Nigeria
}

\author{
M. G. Akinwale \\ Africa Rice Center (Africa Rice), PMB 5320 Ibadan, Nigeria \\ B. O. Akinyele \\ The Federal University of Technology, Akure, Nigeria \\ A. C. Odiyi \\ The Federal University of Technology, Akure, Nigeria \\ F. N. Nwilene \\ Africa Rice Center (Africa Rice), PMB 5320 Ibadan, Nigeria \\ O. S. Osekita \\ Adekunle Ajasin University, Akungba, Nigeria
}

A. Shittu

Africa Rice Center (Africa Rice), PMB 5320 Ibadan, Nigeria

Received: May 14, 2017 Accepted: July 9, 2017 Published: July 11, 2017

Doi: 10.5296/jab.v5i2.11525 URL: http://doi.org/10.5296/jab.v5i2.11525

\begin{abstract}
High yielding rain-fed lowland rice cultivars are sensitive to complete submergence stress of more than four days. In Nigeria, rice farms on about 3.6 million ha of rain-fed lowland areas are adversely affected by submergence stress. Consequently, farmers in the major rice
\end{abstract}


producing states of the country lose their entire crop to flooding each year. The identification of a major quantitative traits locus (QTL) on chromosome 9, designated as sub1, has provided the opportunity to apply marker assisted selection to develop submergence tolerant varieties. This study was undertaken to introgress sub 1 into the genetic background of Nigerian lowland rice mega variety (WITA 4) and assess the ability of WITA 4 with sub 1 to withstand submergence stress. Swarna Sub1, one of the FR13A-derived submergence tolerant varieties developed by IRRI, was crossed to WITA 4, a submergence intolerant Nigerian mega variety to produce $\mathrm{F}_{1}$ hybrid. The derived $\mathrm{BC}_{1} \mathrm{~F}_{2}$ progenies were genotyped and $\mathrm{BC}_{1} \mathrm{~F}_{3}$ phenotyped. The results of genotyping, using two markers, namely ART5 and SC3, revealed that $18 \mathrm{BC}_{1} \mathrm{~F}_{3}$ plants were found carrying Swarna Sub 1 allele of ART5 while $41 \mathrm{BC}_{1} \mathrm{~F}_{3}$ carried WITA 4 allele of ART5. Twenty progenies were found carrying Swarna Sub 1 allele of SC3 while 37 plants carried WITA 4 allele. Two plants carried both alleles $(H)$. Seventeen plants were observed to carry Swarna Sub 1 alleles at both markers loci while a total of 36 progenies were observed to carry WITA 4 alleles at both markers loci. The results of the phenotypic screening showed that 12 plants recorded percentage survival above $60 \%$. The two markers showed high selection accuracies, and selection based on the markers could satisfactorily meet the needs of breeding for submergence.

Keywords: Submergence tolerance, Introgression, Mega rice variety, Quantitative trait loci (QTL)

\section{Introduction}

Rice is a staple food for half of the world population and approximately three quarter of a billion of the world's poorest people depend on it to survive. In Sub-Sahara Africa, over 20 million farmers grow rice and about 100 million people depend on it for their livelihoods (Nwanze et al., 2006). The demand for rice in Nigeria is expected to grow substantially as the population is currently growing at 3-4\% per annum. Productivity in rice production must be increased to attain rice self-sufficiency and satisfy future demands resulting from population growth.

Rain-fed lowland and deepwater rice together accounts for approximately $33 \%$ of global rice farmlands which is about 50 million hectares of the estimated 150 million hectares of rice fields worldwide (Bailey-Serres et al., 2010). Flooding is a serious constraint to rice plant growth and survival in rain-fed lowland and deepwater areas because it results in partial or complete submergence of the plant. In Nigeria, approximately $70 \%$ rain-fed lowland rice farms are prone to this seasonal flooding which is a major constraint to rice production in some major rice producing states, and each year, rice farmers in these parts of the country lose their entire crop to flooding. During any given year, yield losses resulting from flooding may range from 30 percent to total destruction. Recently, the extent of submergence stress has increased due to the effect of climate change such as unpredicted heavy rains that have affected many states along river Niger and Benue. Among the, most frequently and severely affected states in Nigeria are Kebbi, Niger, Kogi and Taraba which account for over $80 \%$ of lowland rice ecology in Nigeria. The experts say the situation may become worst as climate change progresses. Most of the popular high yielding lowland rice varieties such as WITA 4 (FARO 52), SIPI 692033 (FARO 44), TOX 4004-43-1-2-1 (FARO 57) are susceptible to submergence. Even a short period of submergence (seven days) will have tremendous impact 
on the crop stand and yield. Developing submergence tolerant versions of adapted elite rice variety will lead to reduction in yield loss in these areas. Submergence tolerance has long been considered as an important breeding objective for rain-fed lowland and deep water rice areas (Mackill, 1986; Mishra et al., 1996, Septiningsih et al., 2009). Despite this recognition, there has been little success in developing submergence tolerant rice varieties in Africa. Recently, submergence tolerance quantitative trait loci (QTL) contributed by FR13A, a submergence-tolerant landrace from India, has been identified on chromosome 9 in all the mapping studies (Xu \& Mackill, 1996; Nandi et al., 1997; Toojinda et al., 2002). Fine mapping of the QTL on chromosome 9 has been carried out and useful molecular markers for the major QTLs for submergence are now defined and well developed. A further step for breeding submergence tolerant rice is to transfer the relevant QTLs from submergence tolerant donor to a susceptible variety of agronomic importance. Though submergence tolerance is governed by a single major gene (Sub1) which accounts for $70 \%$ phenotypic variation, the transfer of the genomic region containing this gene through conventional breeding combined with marker assisted breeding (MAS) is still the most effective way to develop submergence tolerant variety (Xu et al., 2006). In view of this problem, the present study was undertaken to introgress submergence tolerance gene (Sub1) from Swarna Sub1 varieties developed by IRRI into the genetic background of a Nigerian lowland rice mega variety and assess the effect of the sub1 on the submergence intolerant variety.

\section{Materials and Methods}

Swarna sub1, one of the FR13A-derived submergence-tolerant varieties developed by IRRI was used as the donor of submergence tolerance and crossed to WITA 4, a submergence intolerant maga variety from Nigeria to produce $\mathrm{F}_{1}$ hybrid. $\mathrm{F}_{1}$ plants heterozygous for Sub1 derived from crosses between WITA 4 and Swarna Sub 1 were backcrossed to the recurrent parent (WITA 4) to produced $\mathrm{BC}_{1} \mathrm{~F}_{1}$ plants. The selected $\mathrm{BC}_{1} \mathrm{~F}_{1}$ plants were self pollinated to obtain $\mathrm{BC}_{1} \mathrm{~F}_{2}$. The $\mathrm{BC}_{1} \mathrm{~F}_{2}$ were genotyped using tightly linked polymorphic SSR markers while the derived $\mathrm{BC}_{1} \mathrm{~F}_{3}$ plants were screened for submergence tolerance.

\subsection{Molecular Marker Analysis}

Ten tightly-linked simple sequence repeat (SSR) markers, namely SC3, RM464A, RM5526, RM23805, ART5, RM23887, RM23770, RM8303, RM316 and RM219 reported by Neeraja et al. (2007), Septiningsih et al. (2009) and Xu et al. (2006) were evaluated over the two parents (WITA 4 and Swarna Sub1) for detection of polymorphism. Out of these, four primers were found polymorphic between the two parents. Out of the four polymorphic markers, primers ART5 and SC3 were used for the screening because of their clear co-dominant nature, reproducibility and capability to produce easy-to-score bands.

\subsection{Molecular Genotyping of $60 \mathrm{BC}_{1} F_{2}$ for Confirmation of the Presence of the Subl Locus}

To confirm the presence of the Sub1 locus from $\mathrm{BC}_{1} \mathrm{~F}_{2}$, two of the four polymorphic markers earlier identified, primers SC3 and ART5, were used for the screening of the $60 \mathrm{BC}_{1} \mathrm{~F}_{3}$. DNA was extracted from young leaves of 2-week old plants of the three parents using the protocol of Dellaporta et al. (1983). PCR was performed in volume of $20 \mu 1$ reactors containing $20 \mathrm{ng}$ of template DNA, 10 x PCR buffer (containing $200 \mathrm{mM}$ Tris- $\mathrm{HCl} \mathrm{pH} 8.3,500 \mathrm{mM} \mathrm{KCl,} 15$ $\mathrm{mM} \mathrm{MgCl2}$ ), $1 \mu \mathrm{l}$ of $1 \mathrm{mM} \mathrm{dNTP}, 0.50 \mu \mathrm{l}$ each of $5 \mu \mathrm{M}$ forward and reverse primers and 0.20 
$\mu 1$ of Taq DNA polymerase (4 U/ $\mu \mathrm{l}$ ) using dual 96 -well thermal cycler. The PCR profile used for the reaction consists of an initial step at $94{ }^{\circ} \mathrm{C}$ for $2 \mathrm{~min}, 30$ cycles of $94{ }^{\circ} \mathrm{C}$ for $30 \mathrm{~s}, 55{ }^{\circ} \mathrm{C}$ for $45 \mathrm{~s}$, and $72{ }^{\circ} \mathrm{C}$ for $45 \mathrm{~s}$ and $7 \mathrm{~min}$ at final extension. The PCR amplified fragments were separated in $2 \%$ agarose gel electrophoresis, stained with $0.5 \mathrm{mg} / \mathrm{ml}$ ethidium bromide, and visualized on Transillumination UV light (Model-20, Upland, USA). For each marker, allelic bands were scored on the parent's bands and designated as A for recipient parent's type, B for tolerant parent's type and $\mathrm{H}$ for heterozygote.

\subsection{Phenotyping of 60 BC1F3 Lines to Test the Effect of Sub1 Locus}

Phenotypic evaluations of the $\mathrm{BC}_{1} \mathrm{~F}_{3}$ introgressed lines were conducted at the experimental farm of AfricaRice, Ibadan station, Nigeria during the dry season of 2010. Sixty $\mathrm{BC}_{1} \mathrm{~F}_{3}$ containing sub1 and the two parents were planted in a deep pond tank that allowed maintenance of flood water depth of $1.5 \mathrm{~m}$ for the period of 14 days of submergence. The experimental design adopted is a randomized complete block design with three replicates. Seeds sown in the wet nursery were transplanted after 21 days to the puddled soil in the deep pond at $20 \mathrm{~cm}$ x $20 \mathrm{~cm}$ with one (1) seedling/hill in 2 rows of $2 \mathrm{~m}$ length. Ten extra rows of susceptible varieties (IR 42) were planted on one side of the pond to observe the extent of damage. Nitrogenous fertilizer was applied at $30: 30: 30 \mathrm{~kg} / \mathrm{ha}$ as basal a day before transplanting. Gap-filling was done at 7 days after transplanting to ensure $100 \%$ plant establishment. The transplanted seedlings were allowed to grow for 21 days before submergence. The pond was filled with water to a depth of $1.5 \mathrm{~m}$ to completely submerge plants for a period of 14 days. The required water depth was maintained for the period of 14 days by adding water regularly. 10 plants were randomly uprooted to monitor the extent of damage. The submergence treatment was terminated at the 14th day and the percentage survival data was taken 10 days after de-submergence (IRRI, 2002).

\section{Results}

\subsection{Molecular Marker Analysis}

The results of the marker survey for polymorphism revealed that four SSR markers (RM5526, SC3, RM219 and ART5) out of the ten tightly- linked markers screened were polymorphic between the two parents, showing clear co-dominant pattern and differentiated the recipient parent from the donor parent (Table 1).

Table 1. The list of SSR markers that showed polymorphism between the parents

\begin{tabular}{lll}
\hline Primer name & Forward & Reverse \\
\hline SC3 & AACGCCAAGACCAACTTCC & AGGAGGCTGTCCATCAGGT \\
RM219 & CGTCGGATGATGTAAAGCCT & CATATCGGCATTCGCCTG \\
ART5 & CAGGGAAAGAGATGGTGGA & TTGGCCCTAGGTTGTTTCAG \\
RM 5526 & CACATGATCCTCCACCCACTAGC & GCCTGGCCTCTCTTATCTGTCTACC \\
\hline
\end{tabular}

\subsection{Molecular Genotyping of $60 \mathrm{BC}_{1} \mathrm{~F}_{2}$}

Genotyping of $60 \mathrm{BC}_{1} \mathrm{~F}_{3}$ plants derived from the cross between WITA 4 and Swarna Sub 1, 


\section{Macrothink}

Journal of Applied Biotechnology

ISSN 2327-0640

2017, Vol. 5, No. 2

an FR13A derived submergence tolerance line, using ART5 and SC3 which are tightly linked to submergence QTLs revealed that $18 \mathrm{BC}_{1} \mathrm{~F}_{3}$ plants were found carrying Swarna Sub1 allele of ART5 (scored B) while $41 \mathrm{BC}_{1} \mathrm{~F}_{3}$ carried WITA 4 allele of ART5 (scored A). One progeny could not be scored (Plate 2). Twenty progenies were found carrying Swarna Sub 1 allele of SC3 (scored B) while 37 plants carried WITA 4 allele (scored A). Two plants carried both alleles $(\mathrm{H})$ and one progeny could not be scored (Plate 1). Seventeen plants were observed carrying Swarna Sub 1 alleles at both marker loci (scored B) while a total of 36 progenies were observed carrying WITA 4 alleles at both marker loci (scored A) (Table 2).

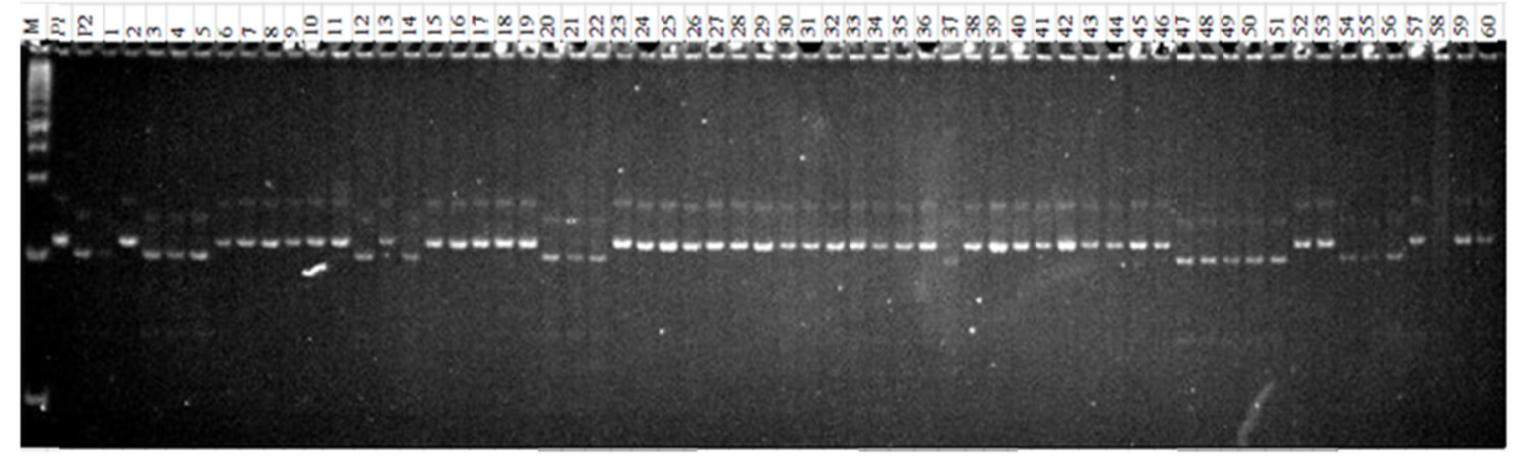

Plate 1. Gel plate showing polymorphic DNA fingerprints of parents and $60 \mathrm{BC} 1 \mathrm{~F} 3$ progeny amplified using tightly - linked SSR primer (ART5), $\mathrm{M}=100 \mathrm{bp}$ ? step DNA ladder, $\mathrm{P} 1=$ parent $1, \mathrm{P} 2=$ parent 2 and 1-60=progeny

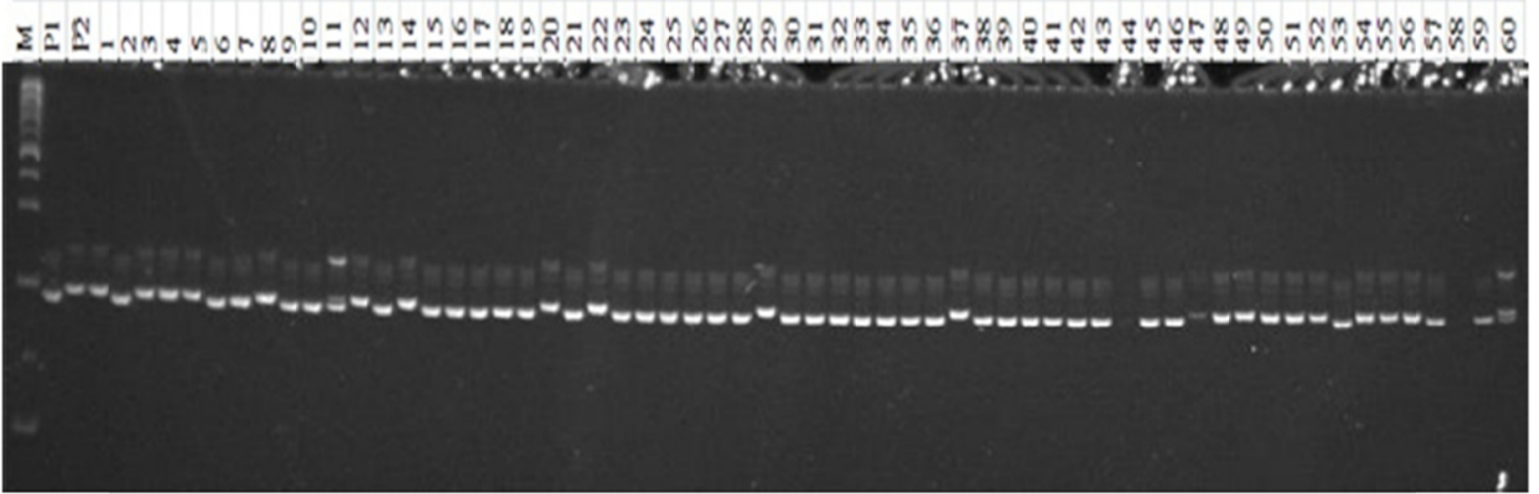

Plate 2. Gel plate showing polymorphic DNA fingerprints of parents and $60 \mathrm{BC}_{1} \mathrm{~F}_{3}$ progeny amplified, using tightly - linked SSR primer (SC3), $\mathrm{M}=100 \mathrm{bp}$ ? step DNA ladder, P1=parent 1, P2=parent 2 and 1-60=progeny 


\section{MInstitute Macrothink $^{m}$}

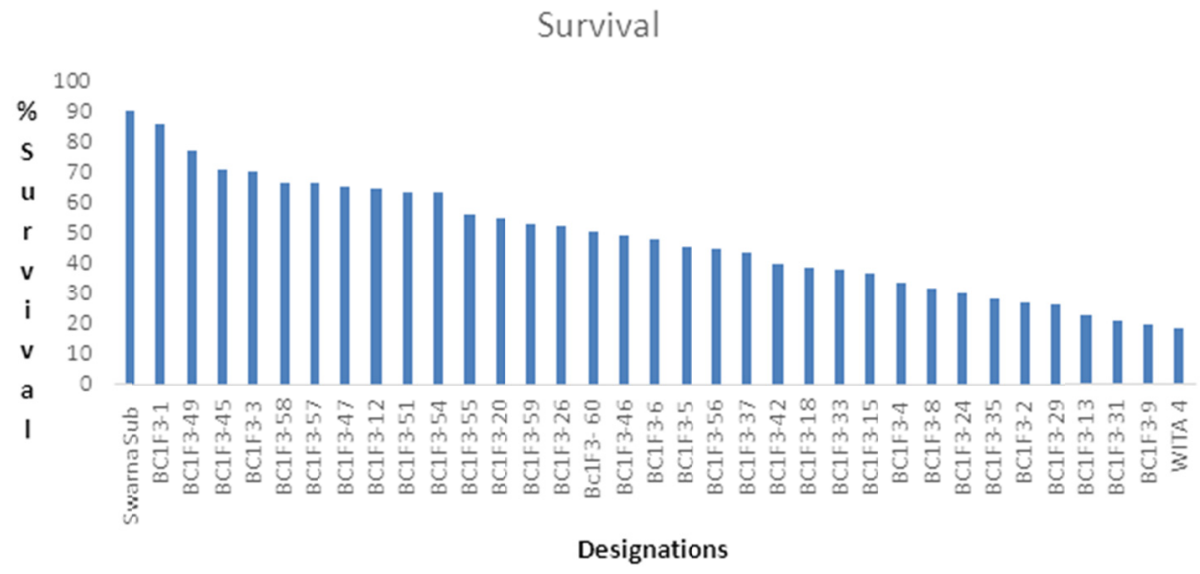

Figure 1. Percentage survival of $\mathrm{BC} 1 \mathrm{~F} 3$ progenies and their parent
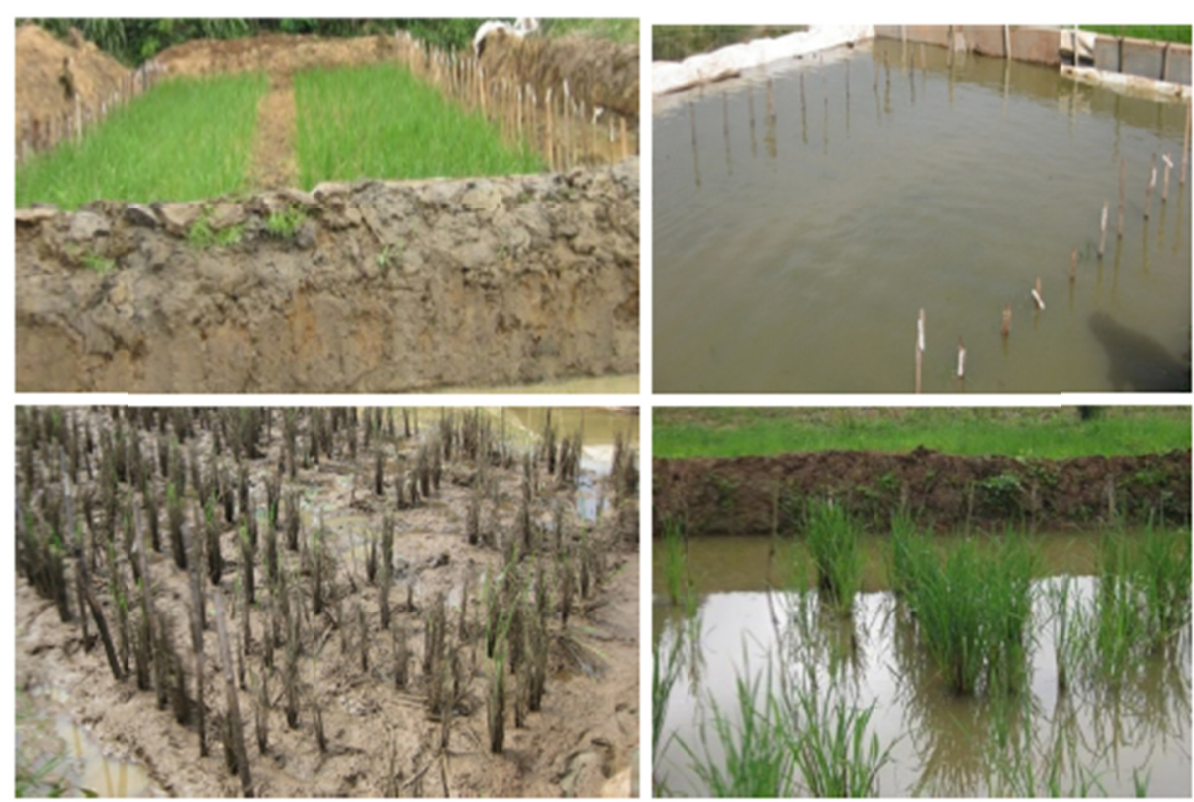

Plate 3. BC1F3 plants undergoing phenotypic screening

Table 2. Genotypic and phenotypic variation in submergence tolerance of BC1F3

\begin{tabular}{ccccccc}
\hline Entry & Designation & $\begin{array}{c}\text { No } \\
\text { Submerged }\end{array}$ & $\begin{array}{c}\text { No } \\
\text { Survived }\end{array}$ & $\begin{array}{c}\% \\
\text { Survival }\end{array}$ & $\begin{array}{c}\text { ART5 } \\
\text { Score }\end{array}$ & SC3 Score \\
\hline E(P1) & WITA 4 & 44 & 8 & 18.18 & A & A \\
E(P2) & Swarna Sub & 44 & 40 & 90.9 & B & B \\
E1 & BC1F3-1 & 44 & 38 & 86.36 & B & B \\
E2 & BC1F3-2 & 44 & 12 & 27.27 & A & A \\
E3 & BC1F3-3 & 44 & 31.12 & 70.73 & B & B \\
E4 & BC1F3-4 & 44 & 14.7 & 33.4 & B & B \\
E5 & BC1F3-5 & 44 & 19.99 & 45.43 & B & B \\
E6 & BC1F3-6 & 44 & 22 & 48.08 & A & A \\
E7 & BC1F3-7 & 44 & 18.13 & 14.29 & A & A \\
\hline
\end{tabular}




\begin{tabular}{|c|c|c|c|c|c|c|}
\hline E8 & BC1F3-8 & 44 & 14 & 31.82 & $\mathrm{~A}$ & $\mathrm{~B}$ \\
\hline E9 & BC1F3-9 & 44 & 8.8 & 20 & A & $\mathrm{A}$ \\
\hline E10 & $\mathrm{BC} 1 \mathrm{~F} 3-10$ & 44 & 11.94 & 27.13 & A & A \\
\hline E11 & BC1F3-11 & 44 & 13.64 & 31.82 & A & $\mathrm{H}$ \\
\hline E12 & BC1F3-12 & 44 & 28.45 & 64.66 & $\mathrm{~B}$ & B \\
\hline E13 & BC1F3-13 & 44 & 10 & 22.73 & A & A \\
\hline E14 & BC1F3-14 & 44 & 14 & 31.82 & $\mathrm{~B}$ & $\mathrm{~B}$ \\
\hline E15 & BC1F3-15 & 43 & 15.64 & 36.36 & A & A \\
\hline E16 & $\mathrm{BC} 1 \mathrm{~F} 3-16$ & 44 & 8 & 18.18 & A & A \\
\hline E17 & BC1F3-17 & 44 & 6.1 & 13.63 & A & $\mathrm{A}$ \\
\hline E18 & BC1F3-18 & 44 & 17 & 38.63 & A & A \\
\hline E19 & BC1F3-19 & 44 & 8.19 & 18.16 & A & $\mathrm{A}$ \\
\hline E20 & BC1F3-20 & 44 & 24 & 54.55 & B & $\mathrm{B}$ \\
\hline E21 & $\mathrm{BC} 1 \mathrm{~F} 3-21$ & 44 & 12.12 & 27.27 & $\mathrm{~B}$ & A \\
\hline E22 & BC1F3-22 & 44 & 13.72 & 31.25 & $\mathrm{~B}$ & $\mathrm{~B}$ \\
\hline E23 & $\mathrm{BC} 1 \mathrm{~F} 3-23$ & 44 & 4.04 & 9.09 & A & A \\
\hline E24 & $\mathrm{BC} 1 \mathrm{~F} 3-24$ & 44 & 13.13 & 30.06 & A & A \\
\hline E25 & BC1F3-25 & 44 & 11.58 & 26.32 & A & A \\
\hline E26 & BC1F3-26 & 44 & 18.51 & 52.04 & A & A \\
\hline E27 & $\mathrm{BC} 1 \mathrm{~F} 3-27$ & 44 & 12.35 & 28.07 & A & $\mathrm{A}$ \\
\hline E28 & $\mathrm{BC} 1 \mathrm{~F} 3-28$ & 44 & 5.54 & 12.6 & A & A \\
\hline E29 & BC1F3-29 & 44 & 11.84 & 26.9 & A & B \\
\hline E30 & BC1F3-30 & 44 & 14.53 & 33.04 & A & A \\
\hline E31 & BC1F3-31 & 44 & 9.36 & 21.06 & A & A \\
\hline E32 & BC1F3-32 & 43 & 14.54 & 31.06 & A & A \\
\hline E33 & BC1F3-33 & 40 & 15.16 & 37.7 & A & A \\
\hline E34 & $\mathrm{BC} 1 \mathrm{~F} 3-34$ & 44 & 10.42 & 22.6 & A & A \\
\hline E35 & BC1F3-35 & 44 & 12.4 & 28.18 & $\mathrm{~A}$ & A \\
\hline E36 & BC1F3-36 & 44 & 10 & 22 & A & A \\
\hline E37 & $\mathrm{BC} 1 \mathrm{~F} 3-37$ & 44 & 19.2 & 43.63 & $\mathrm{~B}$ & B \\
\hline E38 & BC1F3-38 & 44 & 8.18 & 18.6 & A & A \\
\hline E39 & BC1F3-39 & 44 & 2.7 & 5.6 & A & A \\
\hline $\mathrm{E} 40$ & $\mathrm{BC} 1 \mathrm{~F} 3-40$ & 44 & 11.7 & 26.6 & $\mathrm{~A}$ & A \\
\hline E41 & BC1F3-41 & 44 & 5.2 & 11.8 & A & A \\
\hline $\mathrm{E} 42$ & $\mathrm{BC} 1 \mathrm{~F} 3-42$ & 44 & 17.38 & 39.5 & A & A \\
\hline E43 & BC1F3-43 & 44 & 10.42 & 22.6 & A & A \\
\hline E44 & $\mathrm{BC} 1 \mathrm{~F} 3-44$ & 44 & 8.42 & 18.4 & A & A \\
\hline $\mathrm{E} 45$ & BC1F3-45 & 44 & 21.42 & 48.41 & A & A \\
\hline E46 & BC1F3-46 & 43 & 21.69 & 49.29 & A & A \\
\hline E47 & BC1F3-47 & 44 & 28.84 & 65.55 & $\mathrm{~B}$ & B \\
\hline E48 & BC1F3-48 & 44 & 30.81 & 70.05 & $\mathrm{~B}$ & B \\
\hline E49 & BC1F3-49 & 44 & 34.12 & 77.65 & $\mathrm{~B}$ & B \\
\hline E50 & $\mathrm{BC} 1 \mathrm{~F} 3-50$ & 44 & 9.7 & 22.04 & $\mathrm{~B}$ & $\mathrm{~B}$ \\
\hline
\end{tabular}




\section{Macrothink}

$\begin{array}{lllllll}\text { E51 } & \text { BC1F3-51 } & 44 & 28.1 & 63.86 & \text { B } & \text { B } \\ \text { E52 } & \text { BC1F3-52 } & 44 & 29.12 & 66.4 & \text { A } & \text { B } \\ \text { E53 } & \text { BC1F3-53 } & 40 & 21.71 & 54.4 & \text { A } & \text { A } \\ \text { E54 } & \text { BC1F3-54 } & 44 & 27.5 & 63.4 & \text { B } & \text { B } \\ \text { E55 } & \text { BC1F3-55 } & 44 & 24.7 & 56.13 & \text { B } & \text { B } \\ \text { E56 } & \text { BC1F3-56 } & 44 & 19.72 & 44.81 & \text { B } & \text { B } \\ \text { E57 } & \text { BC1F3-57 } & 44 & 29.3 & 66.6 & \text { A } & \text { A } \\ \text { E58 } & \text { BC1F3-58 } & 44 & 29.51 & 67.04 & . & \text {. } \\ \text { E59 } & \text { BC1F3-59 } & 44 & 23.44 & 53.27 & \text { A } & \text { A } \\ \text { E60 } & \text { Bc1F3-60 } & 44 & 22.23 & 50.52 & \text { A } & \text { H }\end{array}$

Note: $\mathrm{A}=$ progeny carrying marker allele of susceptible parent (WITA 4), B = progeny carrying marker allele of tolerant donor parent (Swarna Sub 1) and $\mathrm{H}=$ Heterozygous (progeny carrying marker alleles of both parents).

\subsection{Phenotyping of $B C_{1} F_{3}$ Lines to Test the Effect of Submergence in the Genetic Background of Wita 4}

Plate 3 shows BC1F3 plants undergoing phenotypic screening. Considerable phenotypic variations in submergence tolerance were observed among the $\mathrm{BC}_{1} \mathrm{~F}_{3}$ progenies and the parents 14 days after complete submergence. Survival percentage varied from $5.60 \%$ to $86.36 \%$ for $\mathrm{BC}_{1} \mathrm{~F}_{3}$ (Table 2). The tolerant and susceptible parents recorded 90.90 and $18.18 \%$ respectively. Some differences in the level of tolerance were observed among the BC progenies (Figure 1). The results of the phenotypic screening showed that 12 plants $(\mathrm{E} 1,3,12$, $45,47,48,49,51,52,54,57$ and 58) recorded percentage survival of $86.36,70.73,64.66$, $71.41,65.55,70.05,77.65,63.86,66.40,63.40,66.60$ and 67.04) respectively. All were above $60 \%$ (Table 2).

\section{Discussion}

Normally, molecular markers should be diagnostic for several traits in a wide range of parent materials. In other words, markers should clearly discriminate between varieties that express and those that do not express the trait. Unfortunately, in practice, DNA markers are not always diagnostic due to different genetic backgrounds. The results of the marker survey of reported tightly-linked markers for polymorphism revealed that four (RM5526, SC3, RM219, ART5) of the ten tightly-linked SSR primers screened for a target locus showed fragments that were polymorphic between the two parents, showing clear co-dominant pattern and differentiated the recipient parent from the donor parent (Neeraja et al., 2007; Septiningsih et al., 2009; Xu et al., 2006)

Genetically, it has been observed that QTLs identified in a particular mapping population may not be effective in different backgrounds (Liao et al., 2001). In most cases, the effect of a QTL may differ in different genetic backgrounds due to interactions with either loci or epistasis (Holland, 2001 and $\mathrm{Li}, 2000$ ). Consequently, the effect of submergence tolerance QTLs and the effectiveness of using tightly linked markers to predict phenotype were assessed in the genetic background of WITA 4. The amplification of DNA from the 60 plants with ART5 primers indicated that 18 plants showed resistant banding pattern as the donor 
parent (score B) and 41 showed susceptible banding pattern as the recurrent parent (score A) did. Similarly, the amplification of DNA from the same $60 \mathrm{BC} 1 \mathrm{~F} 3$ plants with gene-based SC3 primers detected 20 plants carrying resistant band of Swarna Sub 1 (score B), two heterozygous carrying both alleles of both parents (score $\mathrm{H}$ ) and 36 plants carrying allele of recipient parent (score A). The two markers showed high selection accuracies, and selection based on one of the markers could satisfactorily meet the needs of breeding for submergence. The results are in agreement with the findings of Neeraja et al. (2007) and Xu et al. (2004) where the use of the two markers for foreground selection was reported. This suggests that the markers would be widely applicable to rice. Such applicability of this marker to indica rice germplasm would be of great importance because flash flooding occurs more commonly in Africa, and breeding programs in these regions seek to improve submergence tolerance of their rice cultivars.

The results obtained also revealed that submergence tolerance introgressed lines (sub1) exhibited significantly greater tolerance when compared with the recipient parents and other susceptible lines, validating the effectiveness of sub1 in conferring submergence tolerance. The results confirmed the observation of Sarkar et al. (2009), Septiningsih et al. (2009) and Singh et al. (2009) that varieties with sub1 gene have substantial level of tolerance to submergence stress. This implies that introgression of submergence tolerance gene into African varieties will provide protection against crop loss due to submergence and boost crop security for lowland rice farmers. In spite of the high level of tolerance observed among the introgressed lines, some differences in the level of tolerance were observed as revealed by the percentage survival.

\section{Conclusion}

The successful introgression of submergence tolerance QTLs to the genetic background of African varieties clearly shows that submergence tolerance QTLs derived from FR13A works in all genetic backgrounds and that the QTLs could be successfully introgressed into other important lowland rice varieties. Selection based on a single marker is sufficient for foreground selection in breeding purposes. The simultaneous use of (SC3 and ART5) markers should deliver high selection accuracy. Therefore, it is concluded that the use of the primers will be more appropriate for marker-assisted selection of submergence tolerance in the genetic background of lowland rice varieties in Nigeria.

\section{References}

Bailey-Serres, J., Fukao, T., Ronald, P., Ismail, A., Heuer, S., \& Mackill, D. J. (2010). Submergence tolerant rice. Subl's journey from landrace to modern cultivar. Rice, 3, 138-147. https://doi.org/10.1007/s12284-010-9048-5

Dellaporta, S. L., Wood, J., \& Hicks, J. B. (1983). A plant DNA minipreparation: version II. Plant Mol Biol Rep, 1, 19-21. https://doi.org/10.1007/BF02712670

Holland, J. (2001). Epistasis and plant breeding. Plant Breed. Rev, 21, 27-92. https://doi.org/10.1002/9780470650196.ch2

Li, Z. K. (2000). QTL mapping in rice: a few critical considerations. In G. S. Khush, D. S. Brar, \& B. Hardy. (Eds.), Rice Genetics IV (pp. 153-171). Science Publishers, New Delhi.

Liao, C. Y., Wu, P., Hu, B., \& Yi, K. K. (2001). Effects of genetic background and 
environment on QTLs and epistasis for rice (Oryza sativa L.) panicle number. Theor. Appl. Genet, 103, 104-111. https://doi.org/10.1007/s001220000528

Mackill, D. J., Zhang, Z., Redona, E. D., \& Colowi, P. M. (1996). Level of polymorphism and genetic mapping of AFLP markers in rice. Genome, 39, 969-977. https://doi.org/10.1139/g96-121

Mackill, D. J. (1986). Rainfed lowland rice improvement in South and Southeast Asia: results of a survey. In: Progress in rainfed lowland rice. Los Baños: International Rice Research Institute, 115-144.

Mishra, S. B., Senadhira, D., \& Manigbas, N. L. (1996). Genetics of submergence tolerance in rice (Oryza sativa L.). Field Crops Res, 46, 177-181. https://doi.org/10.1016/0378-4290(95)00088-7

Nandi, S., Subudhi, P. K., Senadhira, D., Manigbas, N. L., Sen-Mandi, S., \& Huang, N. (1997). Mapping QTLs for submergence tolerance in rice by AFLP analysis and selective genotyping. Molecular and General Genetic, 255, 1-8. https://doi.org/10.1007/s004380050468

Neeraja, C. N., Maghirang-Rodriguez, R., Pamplona, A., Heuer, S., Collard, B. C. Y., ... Mackill, D. J. (2007). A marker-assisted backcross approach for developing submergence-tolerant rice cultivars. Theor. Appl. Genet, 115, 767-776. https://doi.org/10.1007/s00122-007-0607-0

Nwanze, K. F., Mohapatra, S., Kormawa, P., Keya, S., \& Bruce-Oliver, S. (2006). Perspective: Rice development in sub-Saharan Africa. Journal of the Science of Food and Agriculture, 86, 675-677. https://doi.org/10.1002/jsfa.2415

Sarkar, R. K., Panda, D., Reddy, J. N., Patnaik, S. S. C., Mackill, D. J., \& Ismail, A. M. (2009). Performance of submergence tolerant rice (Oryza sativa) genotypes carrying the Sub1 quantitative trait locus under stressed and non-stressed natural field conditions. Indian J. Agric. Sci, 79, 876-883.

Septiningsih, E. M., Pamplona, A. M., Sanchez, D. L., Neeraja, C. N., Vergara, G. V., ... Mackill, D. J. (2009). Development of Submergence Tolerant Rice Cultivars: The Sub1 Locus and Beyond. Annals of Botany, 103(2), 151-160. https://doi.org/10.1093/aob/mcn206

Singh, S., Mackill, D. J., \& Ismail, A. M. (2009). Responses of SUB1 rice introgression lines to submergence in the field: yield and grain quality. Field Crops Res, 113, 12-23. https://doi.org/10.1016/j.fcr.2009.04.003

Toojinda, T., Siangliw, M., Tragroonrung, S., \& Vanavichit, A. (2002). Molecular genetics of submergence tolerance in rice: QTL analysis of key traits. Annals of Botany, 91, 243-253. https://doi.org/10.1093/aob/mcf072

Xu, K., Xu, X., Fukao, T., Canalas, P., Maghirang-Rodriguez, R., Heuer, S., \& Mackill, D. J. (2006). Sub1A is an ethylene responsive-factor-like gene that confers submergence tolerance to rice. Nature, 442, 705-708. https://doi.org/10.1038/nature04920

$\mathrm{Xu}$, Y. B., Beachell, H., \& McCouch, S. R. (2004). A marker based approach to broadening the genetic base of rice in the USA. Crop Sci, 44, 1947-1959. https://doi.org/10.2135/cropsci2004.1947 


\section{Macrothink}

Xu, K., \& Mackill, D. J. (1996). A major locus for submergence tolerance mapped on rice chromosome 9. Mol Breed, 2, 219-224. https://doi.org/10.1007/BF00564199

\section{Copyright Disclaimer}

Copyright reserved by the author(s).

This article is an open-access article distributed under the terms and conditions of the Creative Commons Attribution license (http://creativecommons.org/licenses/by/3.0/). 